\title{
الرقابة القضائية على سلطات الضبط القطاعية في الجزائر
}

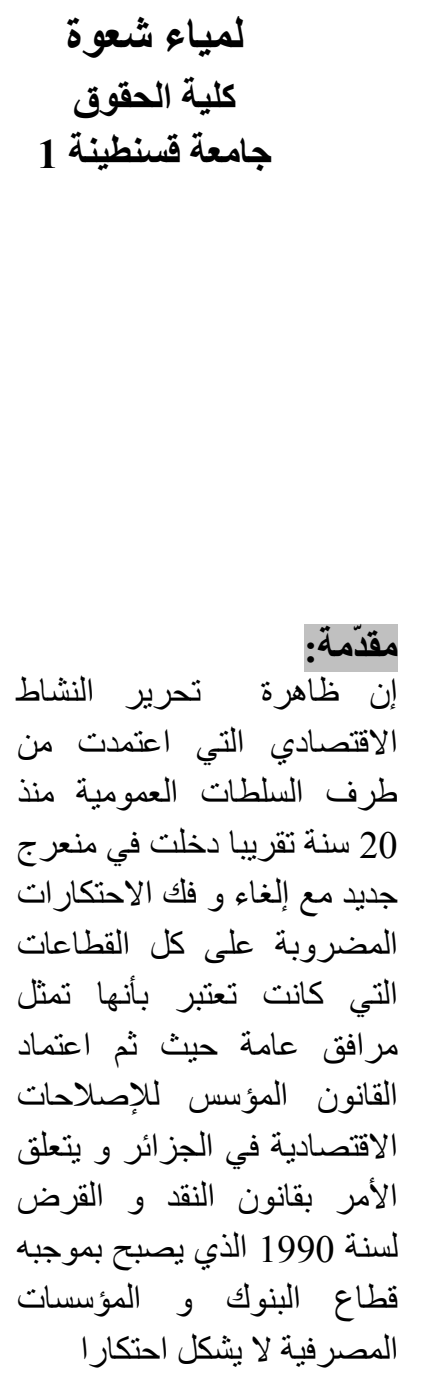

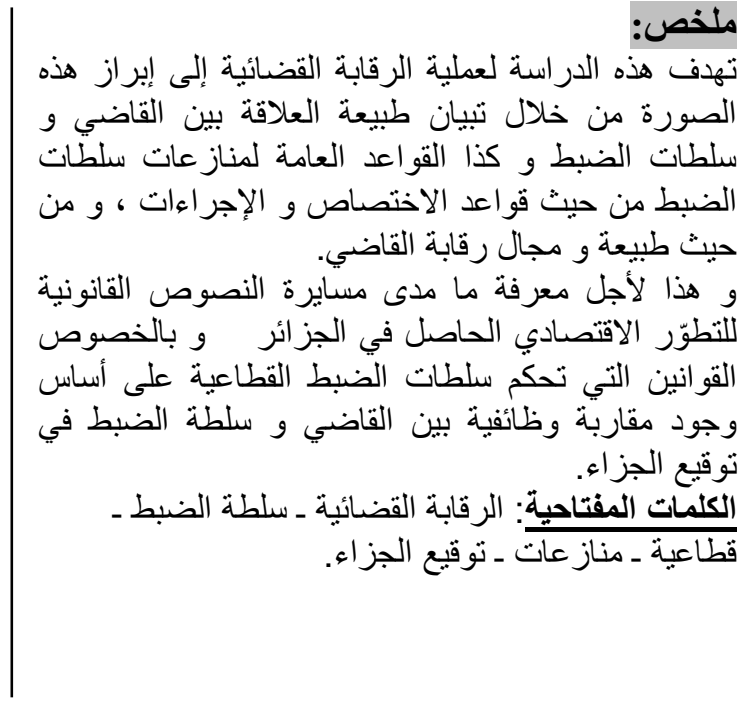

Abstract:

This study of judiciary control process aims to shed light on this mechanism through clarifying the nature of the relationship between the judge and regulation authorities, also the general rules for regulation authorities' disputes considering the competence rules and procedures, and considering the nature and the scope of judge control.

All what precedes is to know the scope of the legal texts accompaniment to the economic development achieved in Algeria, especially the laws that rule the sectorial regulation authorities on the basis of the existence of functional approach between the judge and the regulation authority in imposing punishment.

Keywords: judiciary control - Regulation authority - sectorial - disputes - imposing punishment. 


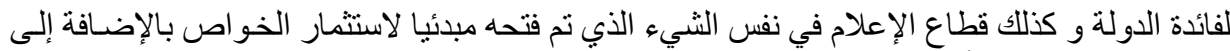

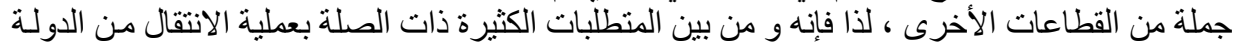

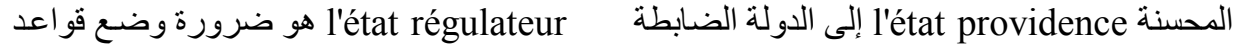

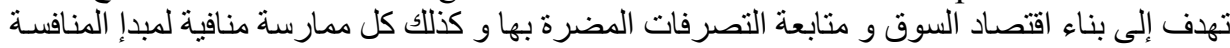

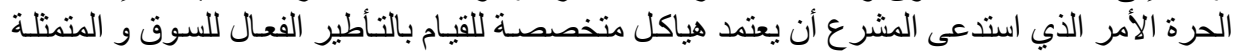

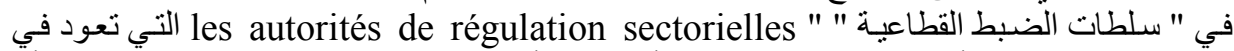

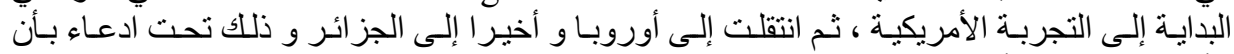

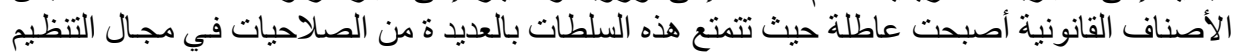

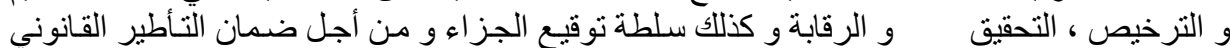

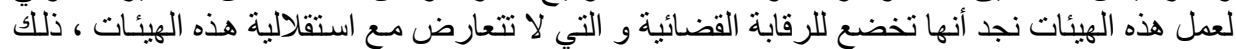

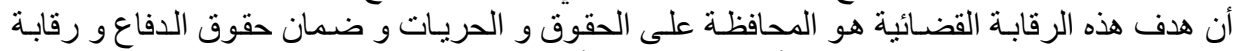

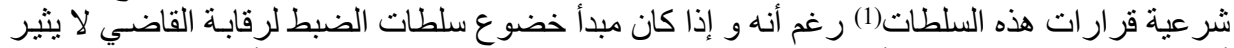

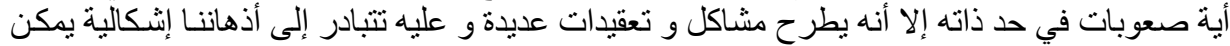

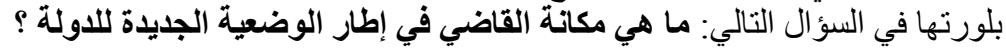

أولا: طبيعة العلاقة بين القاضى و سلطات الضبط:

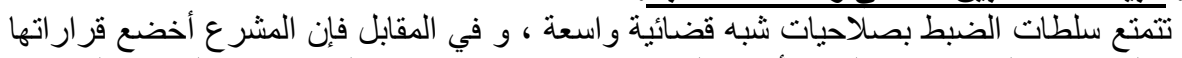

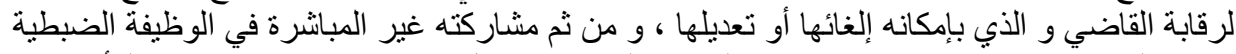

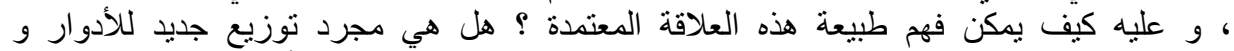

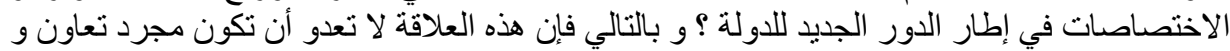

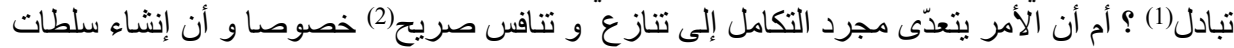

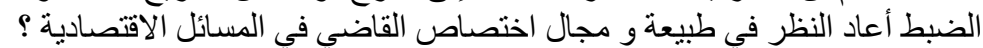

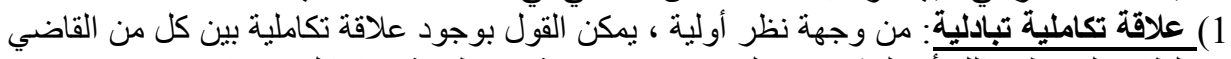

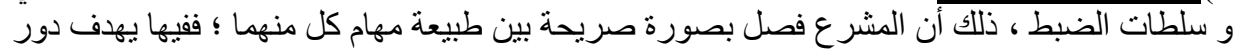

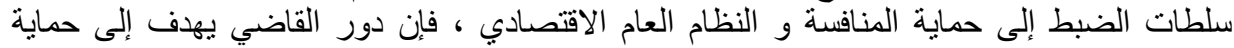

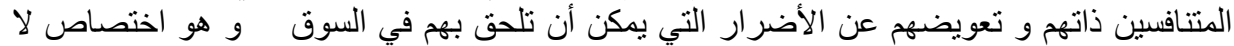

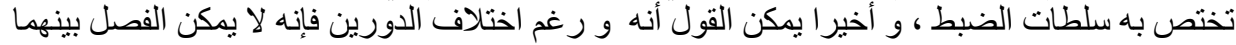
، ذللك أنه و رغم الحدود التي تفرضها طبيعة الدورين إلا أن المشرع أو أوجد جملة آليات تبادلية تكاملية لألية

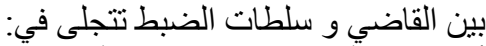

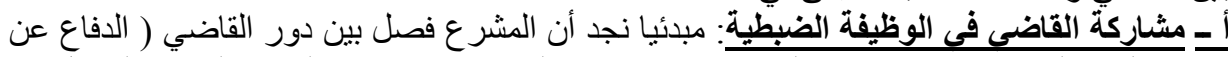

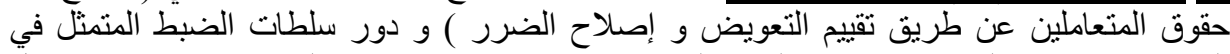

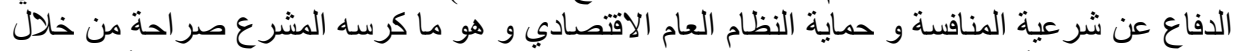

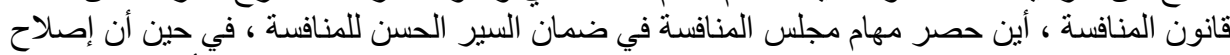

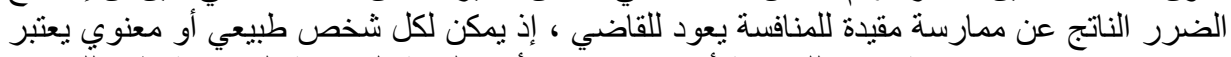

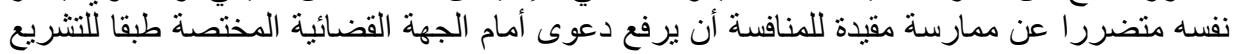

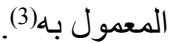

و من ثم فإن العقوبات المالية ( الغرامات ) الناتجة عن الممارسات المقيدة للمنافسة لا تعتبر تعويضا

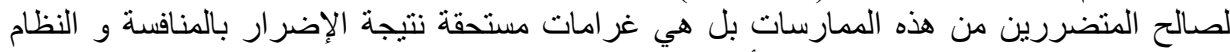

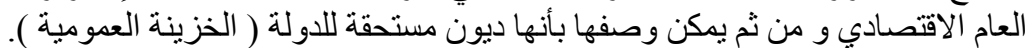

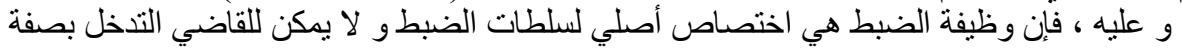

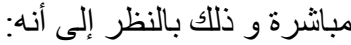
ـ لا يمكن للقاضي إخطار نفسه بنفسه ؛ 


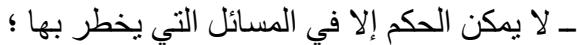

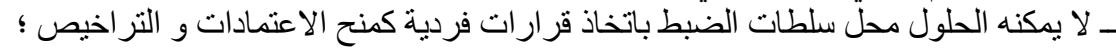

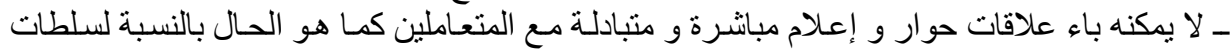

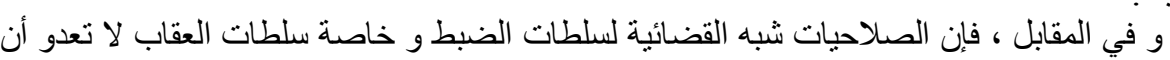

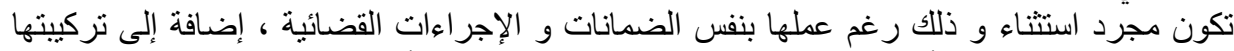
القضائية و الجماعية إلا أن قرار اتها تبقى إدارية و ليست قضائية و أن النيات الاختصاص القضائي يعود في تركية

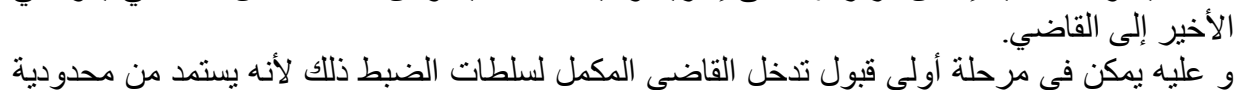

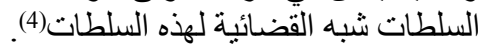

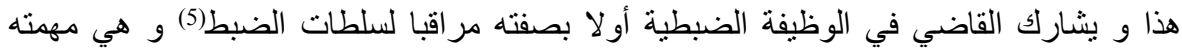

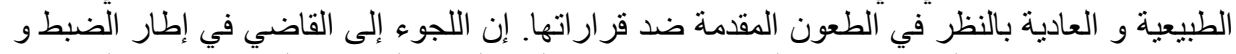

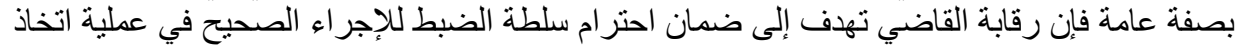

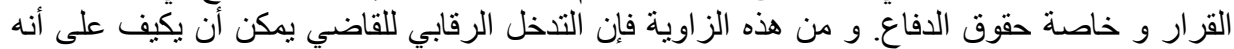
مشاركة غير مباثرة في وظيفة الضبط.

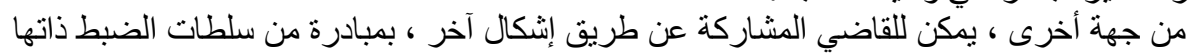

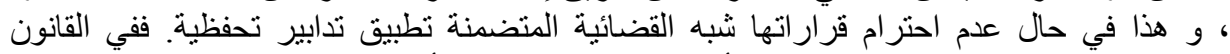

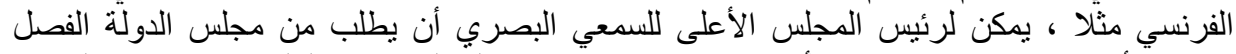

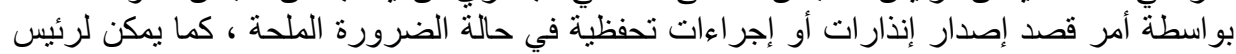

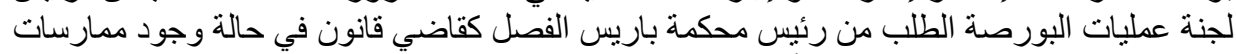

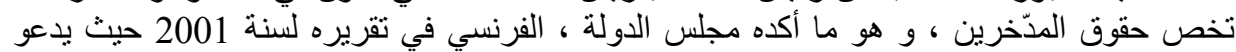

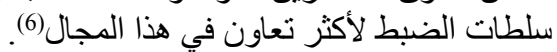
بالنسبة لسلطات الضبط في القانون الجزائري لم بنص الفيط المشرع على هذا الإجراء التكميلي بين

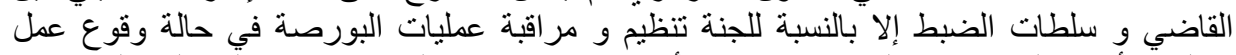

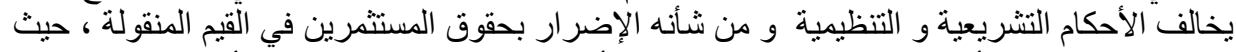

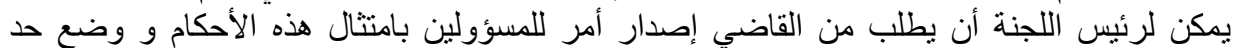

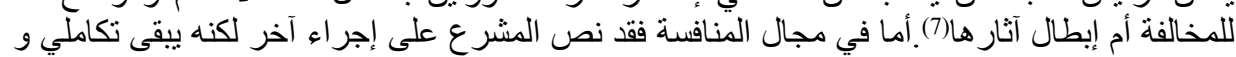

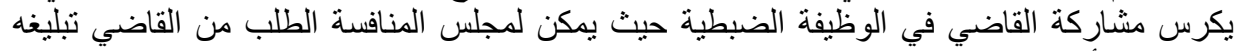

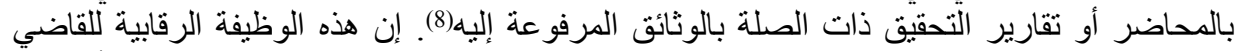

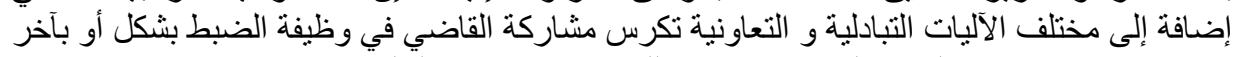

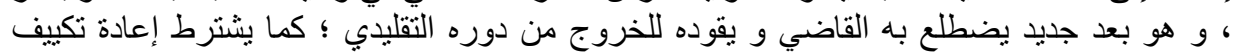
القضاء قصد ممارسة وظائف الضبط لفئ الاقتصادي.

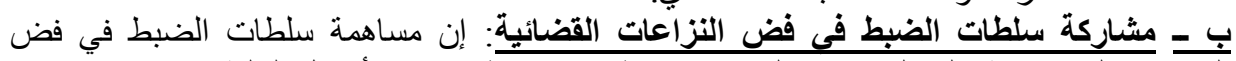

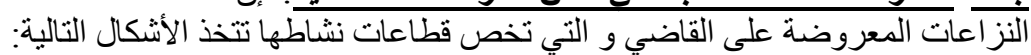

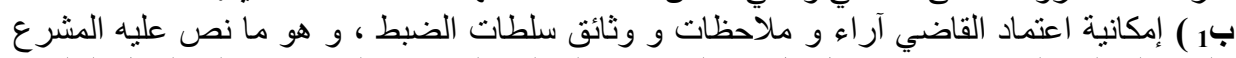

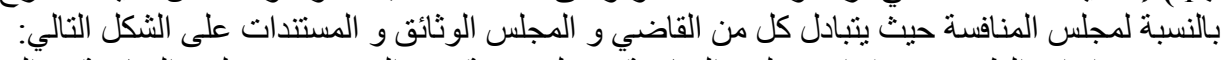

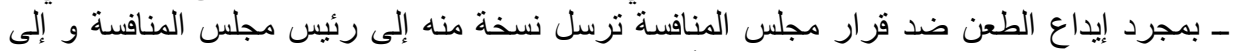

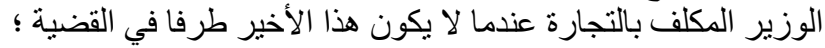

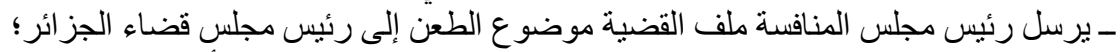

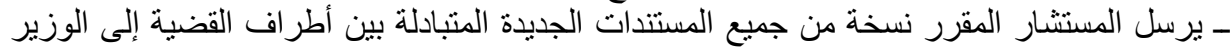

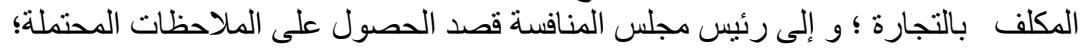


- يمكن للوزير المكلف بالتجارة و رئيس مجلس المنافسة تقديم ملاحظات مكتوبة في آجال يحددها

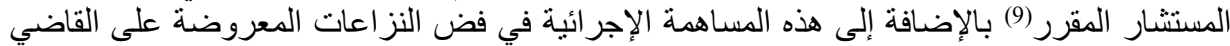

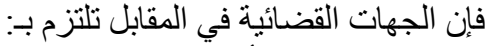

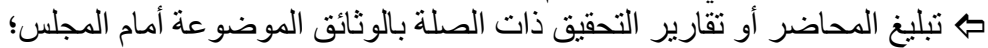

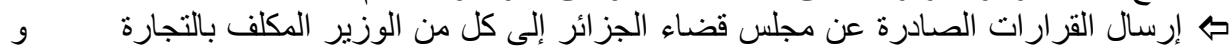
رئيس مجلس المنافسة.

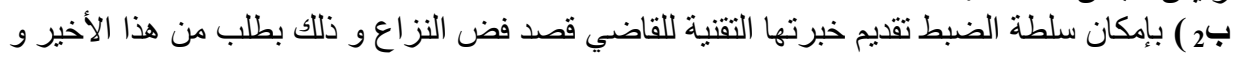

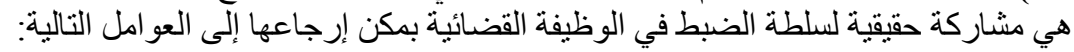

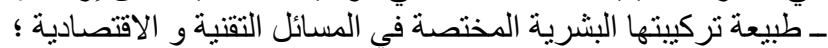

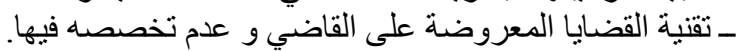

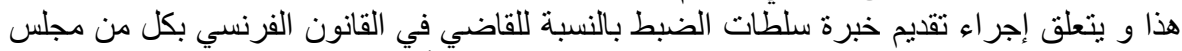

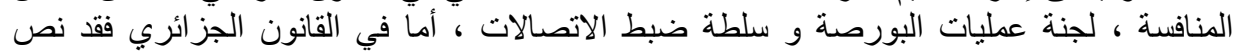

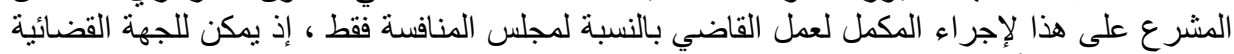

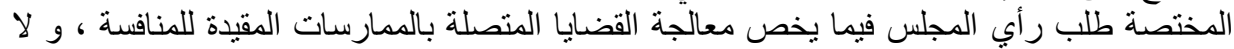

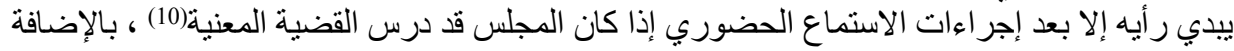

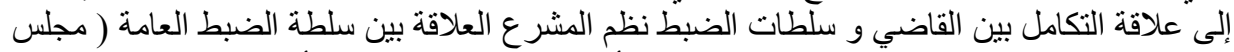

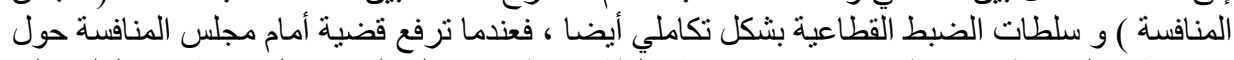

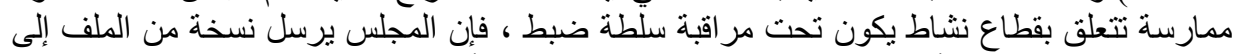

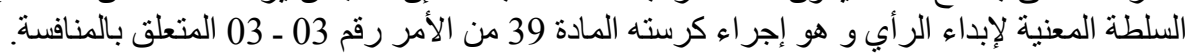

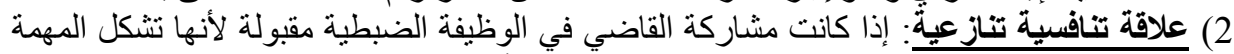

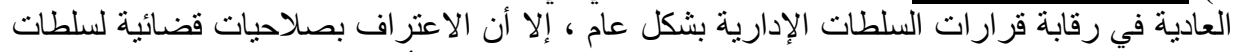

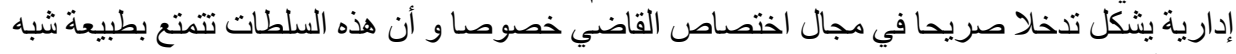
قضائية.

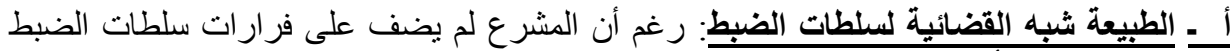

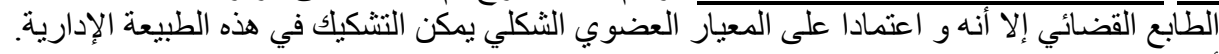

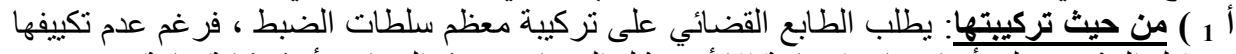

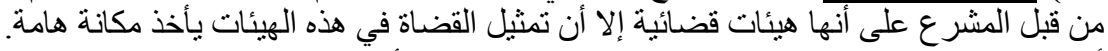

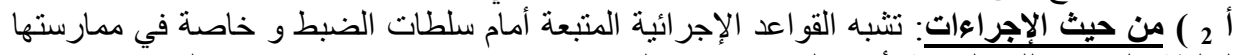

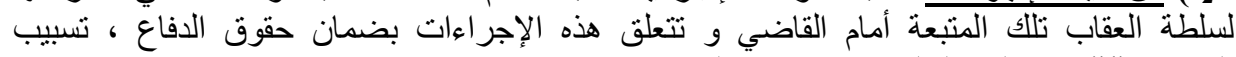

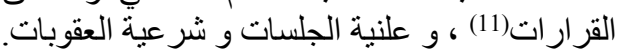

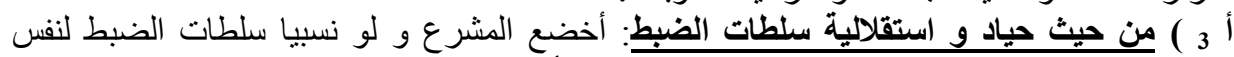

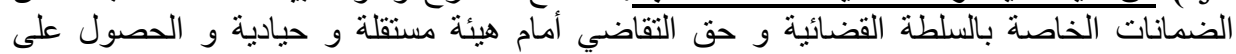

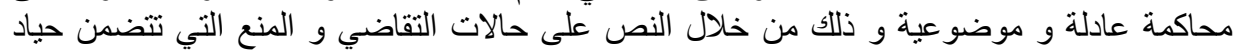
أعضاء هذه السلطات بالنسبة للقطاعات المضات المضبو طنة

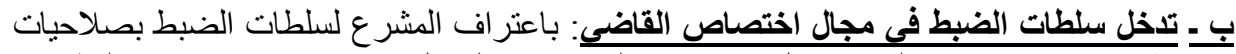

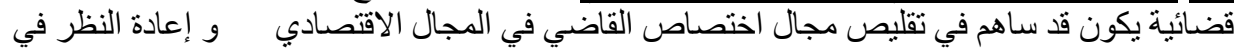

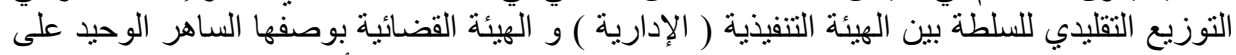

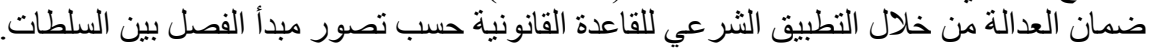

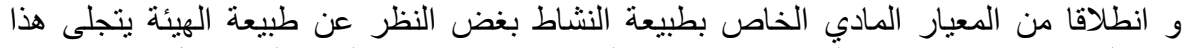

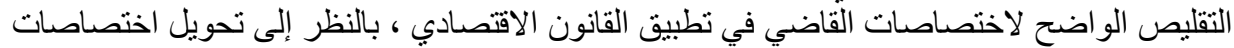
قضائية إلى سلطات الضبط على النحو التنالي: 
ب1 ) من خلال الاختصاصات شبه القضائية المعترف بها لسلطات الضبط و المتعلقة أساسا بوظيفة

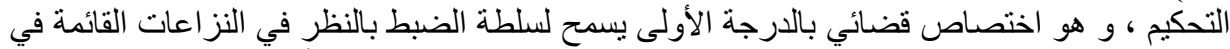

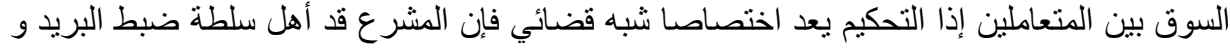

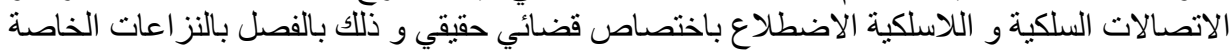

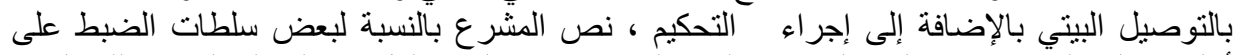

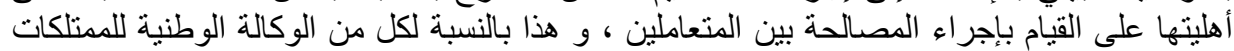

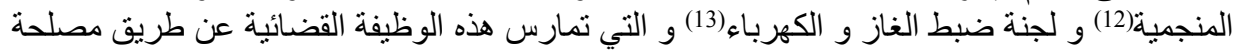

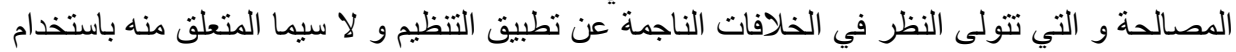
الثيكات و التعريفات و مكافآت التئعاملين.

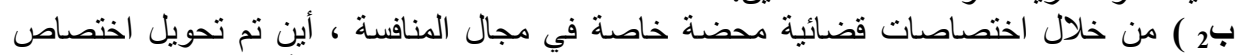

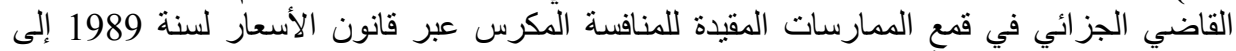

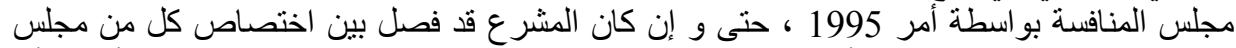

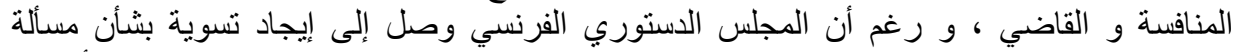

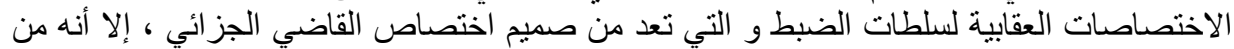
وجهة نظر تقليدية تبقى الممارسة القضائية لسلطات الضبط و هي سلطات إدارية بالدرجة الأولى منافية الإنية لروح مبدأ الفصل بين السلطات.

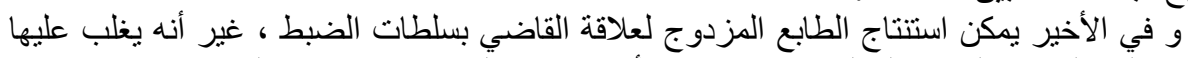

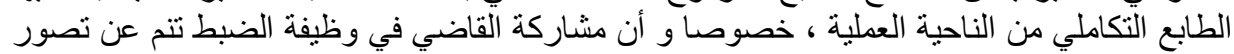

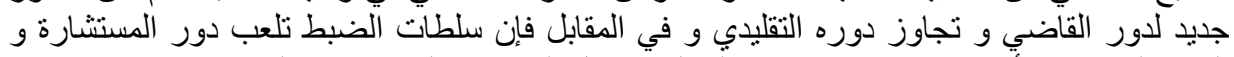

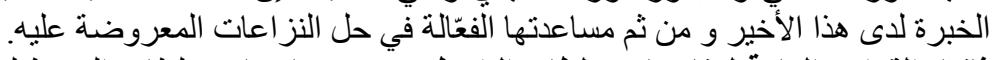

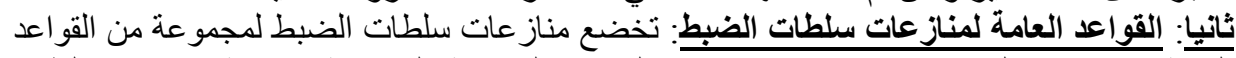

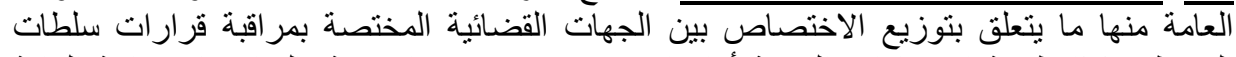

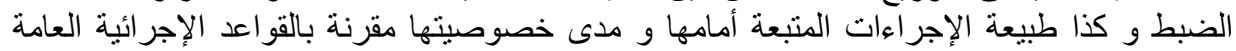

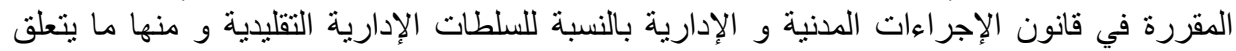

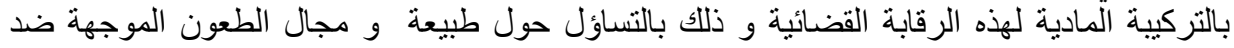

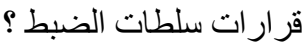

1) من حيث قواعد الاختصاصات و الإجراءات: أخضع المشرع سلطات الضبط باعتبار طبيعتها

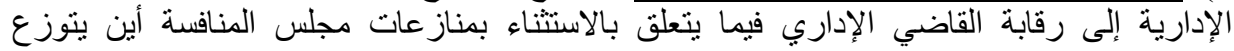

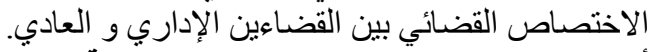

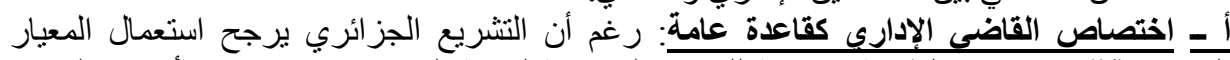

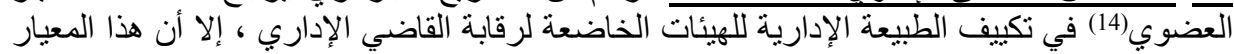

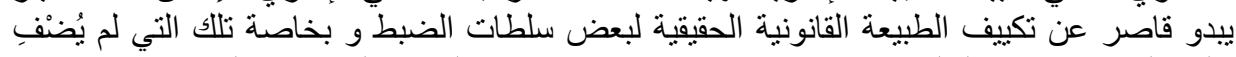

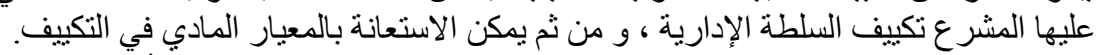

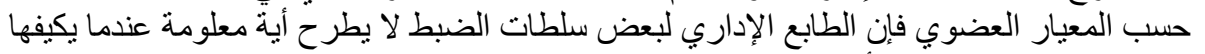

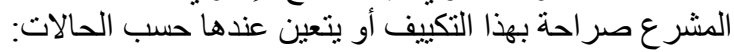

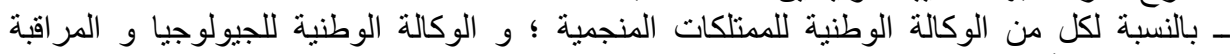

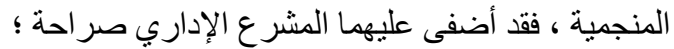

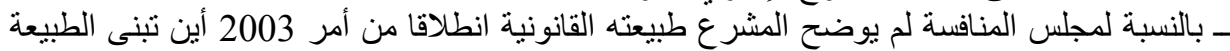

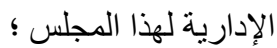
ـ كما كيّف المشر ع صر احة سلطة ضبط المياه على أنها سلطة إدارية(15). 


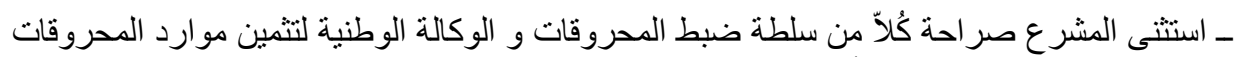

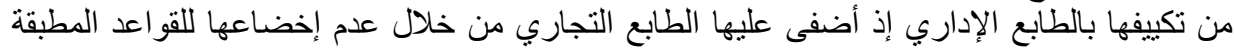

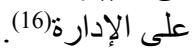

بالنسبة للسلطات الأخرى و التي لم يحدد المشرع صر احة طبيعتها الإدارية ، يمكن استعمال المعيار

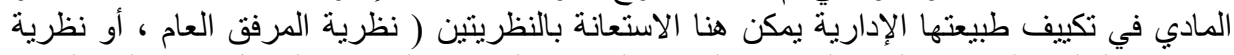

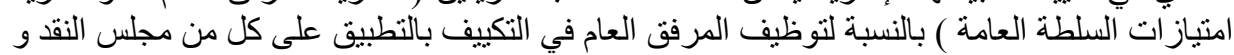

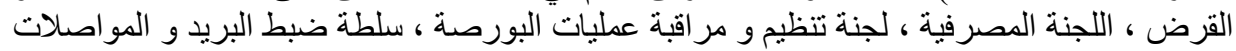

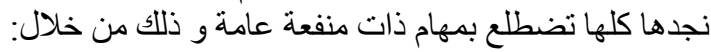

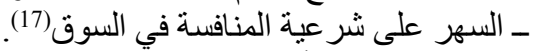
ـ ـمان احتر ام الأحكام التشريعية و التتظيمية من قبل المتعاملين في مختلف القطاعات.

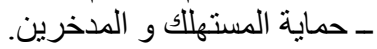
إن كل هذه المهام هي من طبيعة إدارية و تشكل الاختصاص المادئ المادي للسلطات الإدارية ذلك لأنها

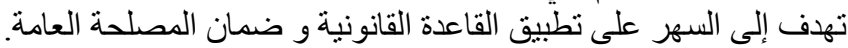

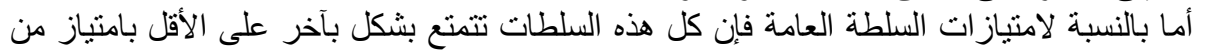

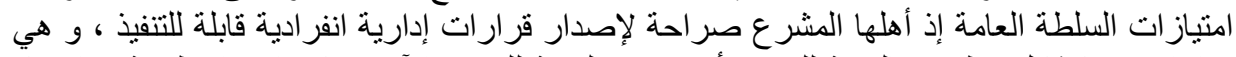

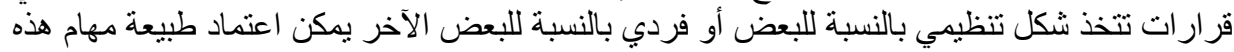

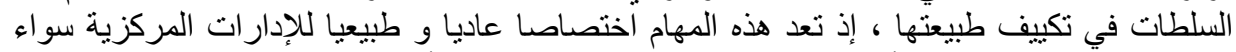

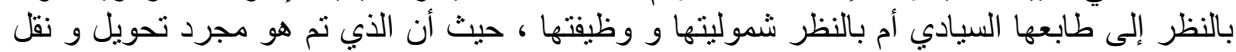

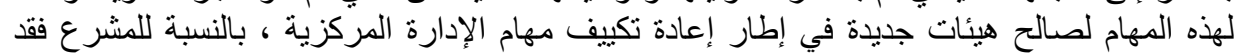

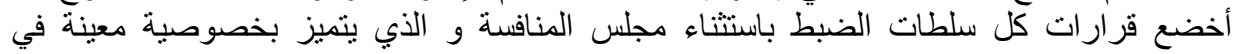

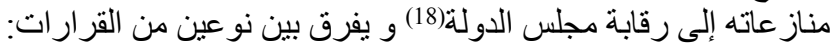

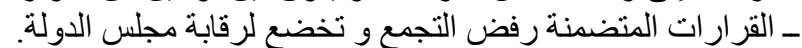
ـ قرارات المجلس المتعلقة بالممارسات المقيدة للمنافسة و هي قابلة المبلة للطعن أمام مجلس قضاء الجز ائر الذي يفصل في المواد التجارية (19).

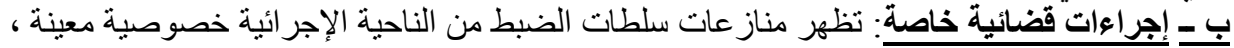

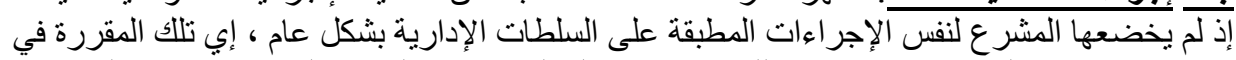

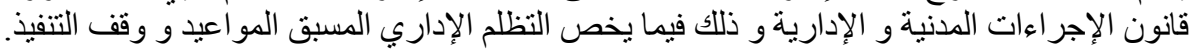

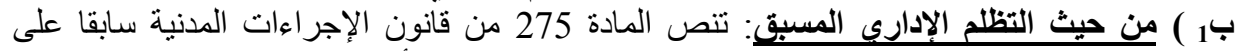

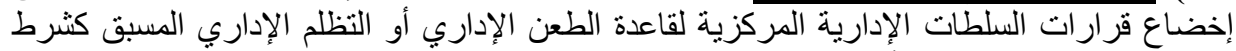

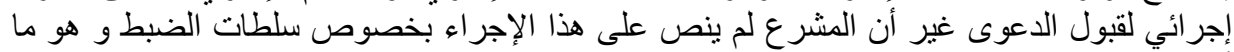

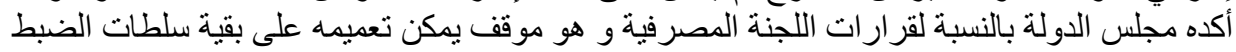

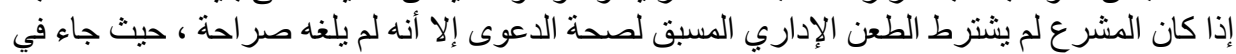

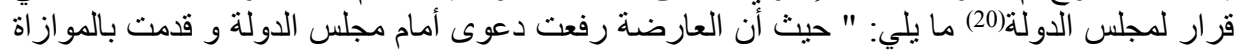

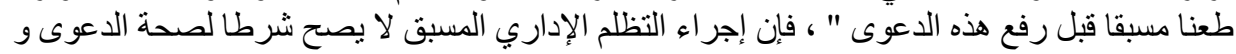

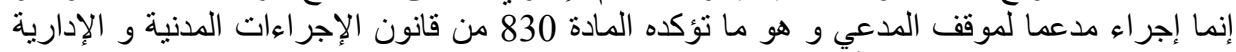

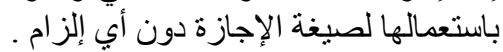

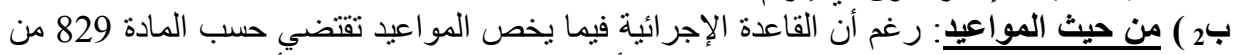

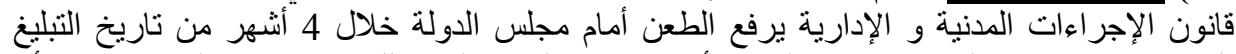

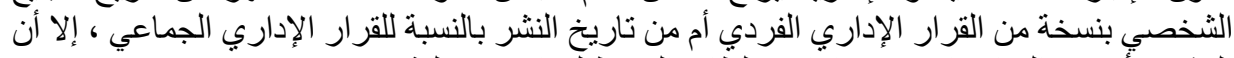

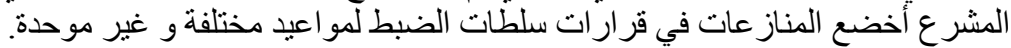

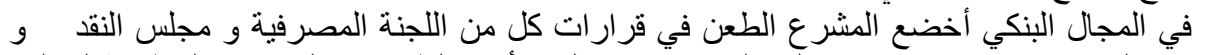
القرض لميعاد ستين يوما من يوم تبليغ القرار سواء تعلق الأمر بالطعن في القرارات التنظيمية لمجلس 


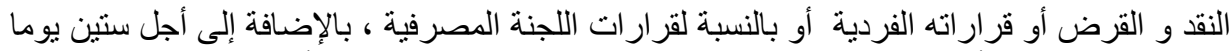

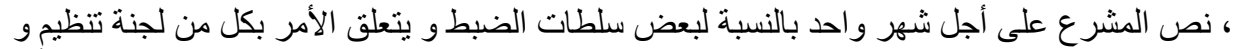

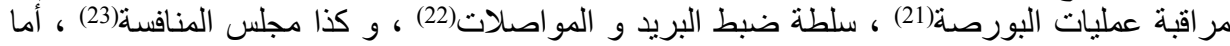

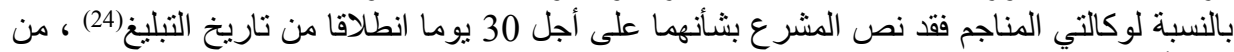

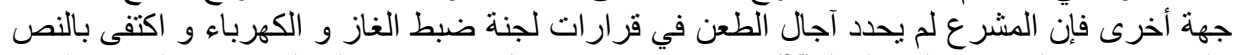

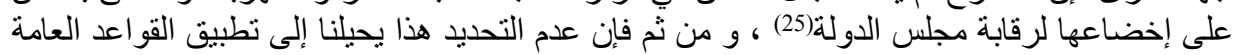

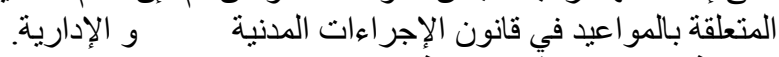

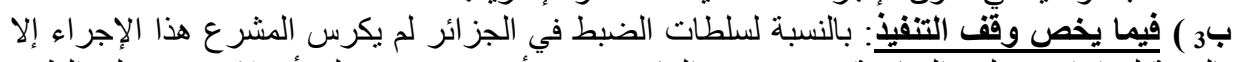

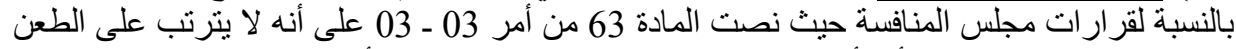

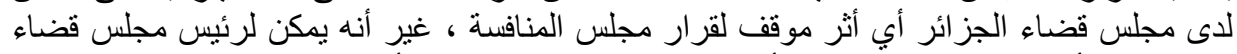

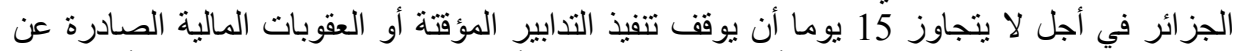

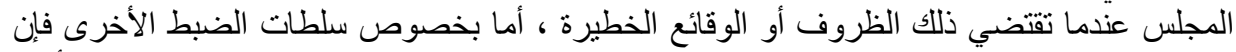

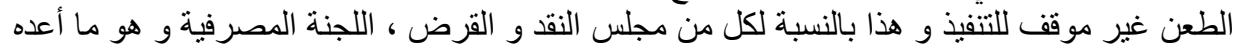

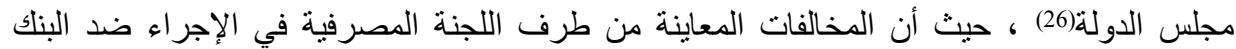

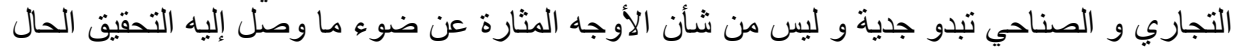

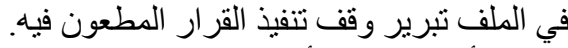

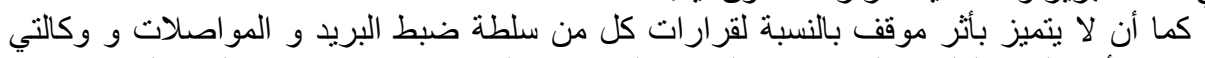

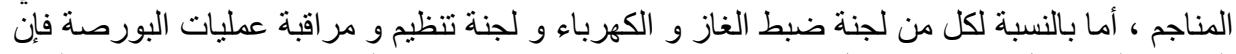

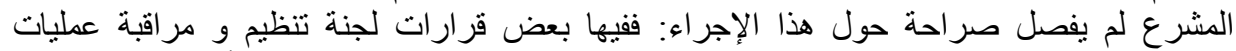

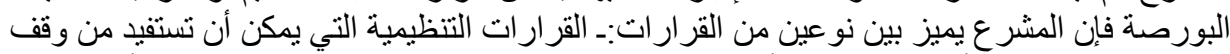

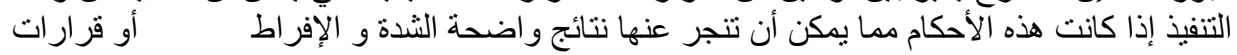

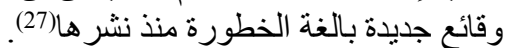

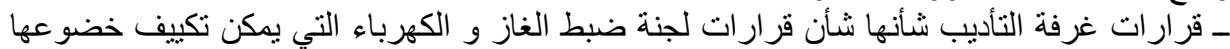

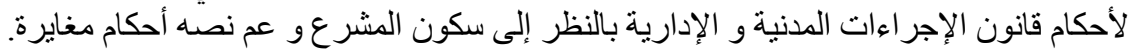

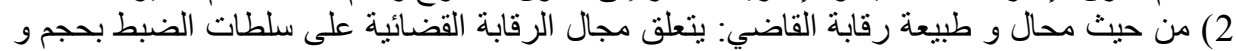

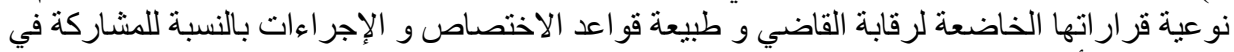
كل نوع من أنو اع قرار اتراتها.

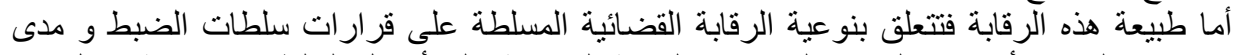

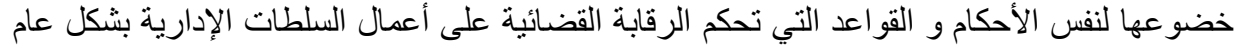

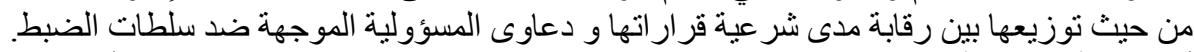

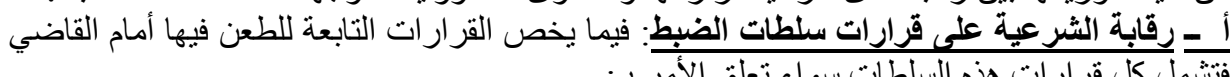

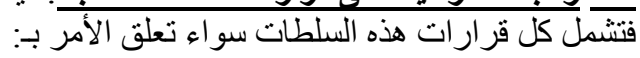

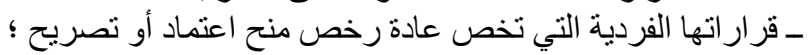

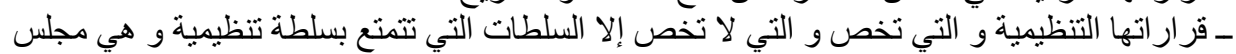

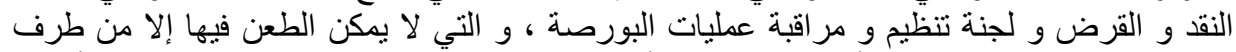

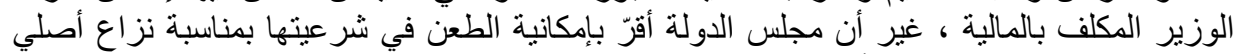

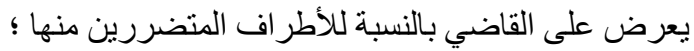

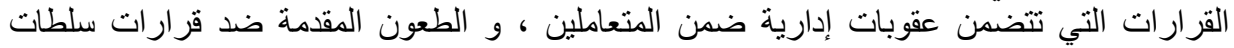

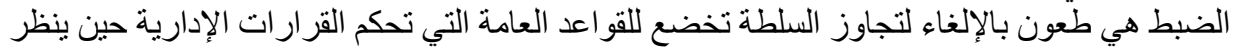
القاضي في رقابة شر عيتها من وجهين: 


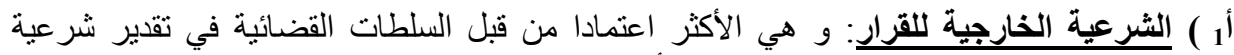

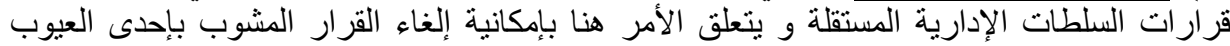

ـ عيب علدم الاختصاص: و هو ما اعتمده مجلس الدولة في فحص شرعية بعض القرارات الخاضعة

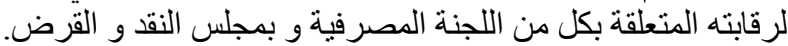

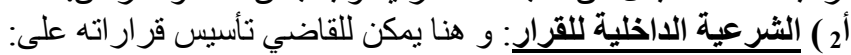

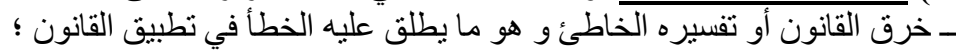
ـ الخطأ في تقدير الوقائع من قبل سلطة الضبط الضبط.

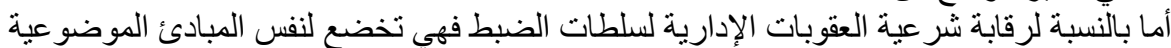

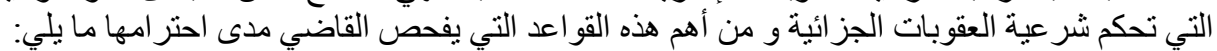

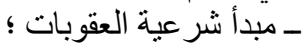
ـ احتر ام مبدأ عدم رجعية القو انين ؛

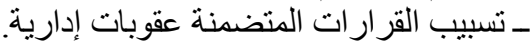

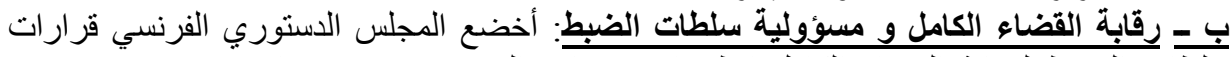

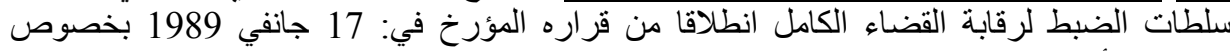

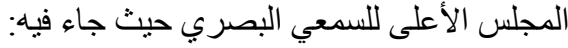
«toute décision du conseil supérieur de l'audiovisuel qui interviendrait en violation des dispositions législatives ou règlementaire serait susceptible d'entraîner la mise en jeu de sa responsabilité de la puissance publique » فإذا كان المبدأ يقضي بإخضاع هذه السلطات لرقابة القضاء الكامل فإنه يعود لاجتهاد القضائي تحديد طبيعة القو اعد المطبقة في مجال مسؤوليتها على قرار انها و ذللك انطلاقا من تحديد طبيعة النشآط الذي لئي

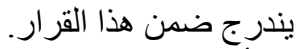

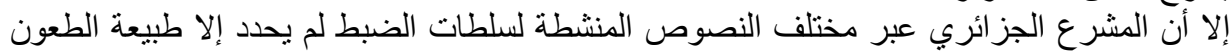

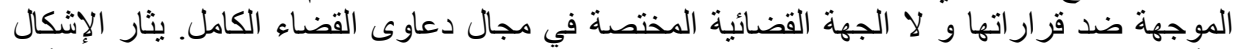

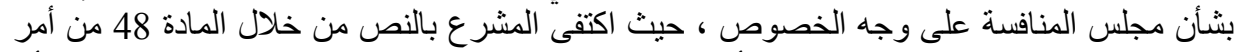

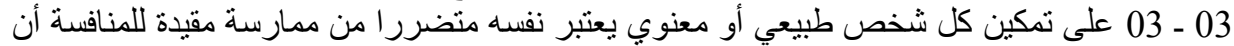

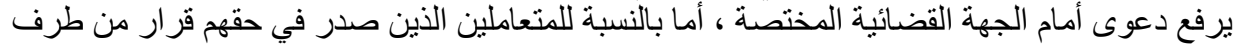

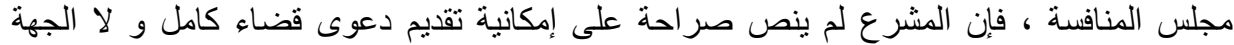

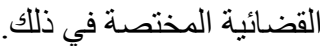
و عليه قصد ضرورة توحيد الاختصاص القضائي بالنظر إلى المادة 98 و التي تمنح اختصاص القاضي فئي

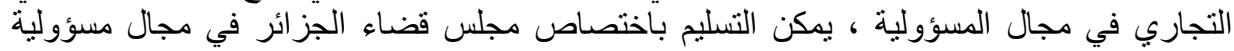

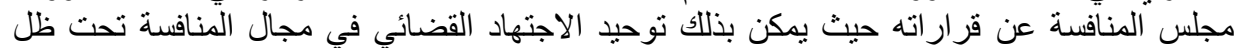
المحكمة العليا. (28) أما بالنسبة لبقية سلطات الضبط ، فإن سكوت المشرع بشأن مسؤوليتها عن أخطائها المرتكبة لا يعفيها

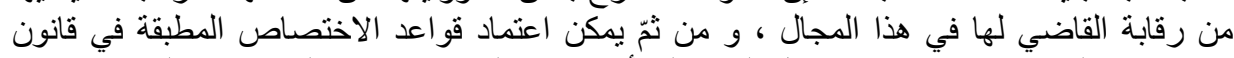

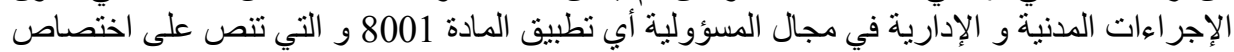
المحاكم الإدارية في المناز عات المختلفة بدعاوى القضية المناء الكامل.

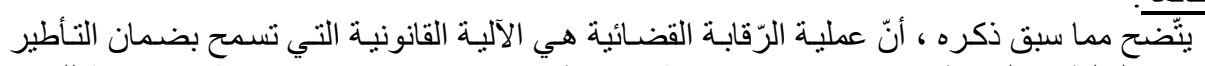

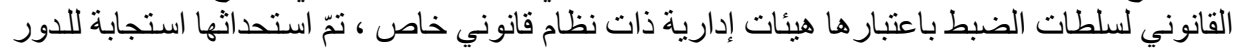

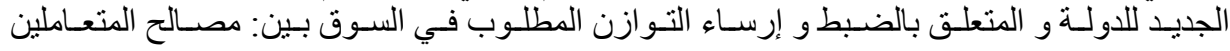




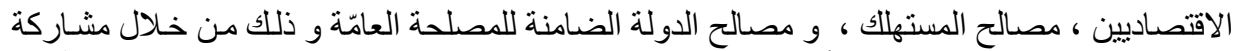

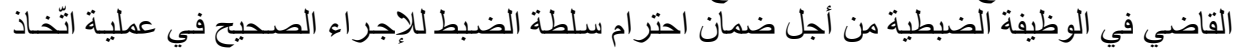

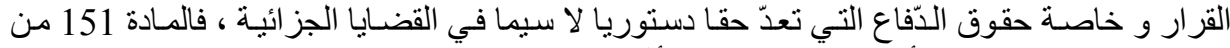

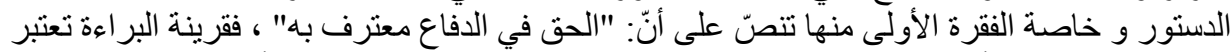

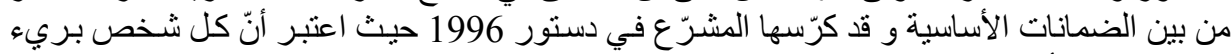

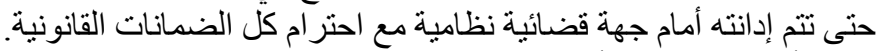

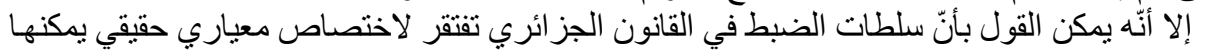

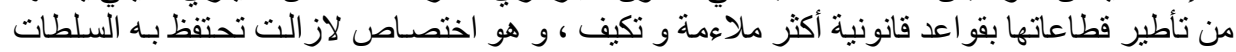

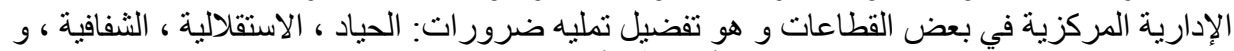

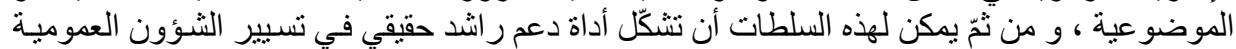

الاقتصادية.

و عليه فإنّ التجربة الجز ائرية بالنظر إلى حداثتها و طبيعة مقاربة المشرّ ع و السلطات العمومية لها

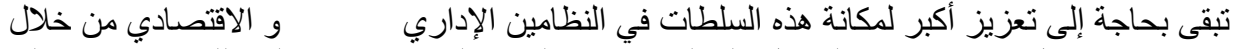

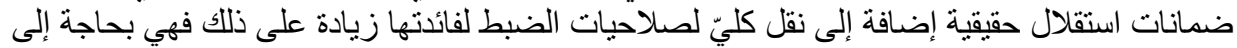

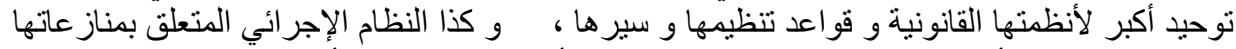

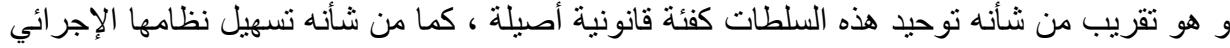

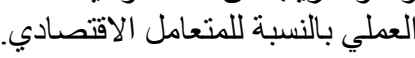

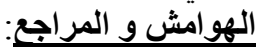

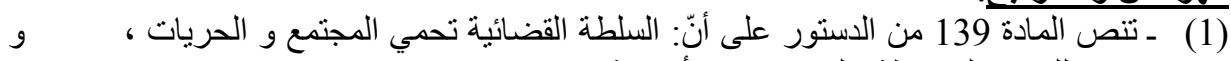
تضمن للجميع المحافظة على حقوقهم الأساسية.

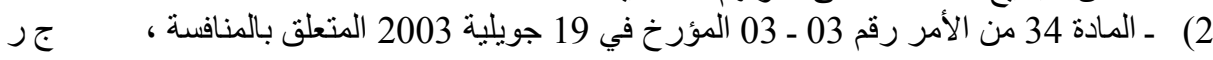

(3) - المادة 48 من نفس الأمر.

4)- f . dupuis . toubol, le juge en en complémentarité du régulateur, les régulations économiques, opcit, p135.

5)- c . bellamy, le juge contrôleur du régulateur, les régulations économiques, opcit, p174.

6)- conseil d'etat, opcit , p329.

(7) ـ المادة 40 من القانون رقم 03 - 04 المؤرخ في 17 فيفري 2004 المتعلق ببورصة القيم المنقولة

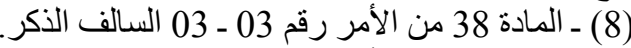

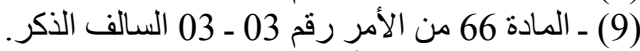

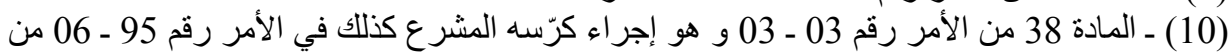

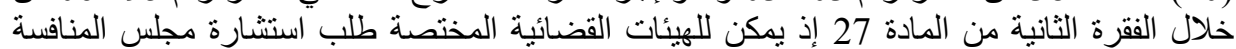
لمعالجة القضايا المعروضة الئة عنيها

(11) ـ نص المشرع في المادة 150 من القانون رقم 02 - 01 بخصوصاء الكوض سلطة العقاب للجنة ضبط

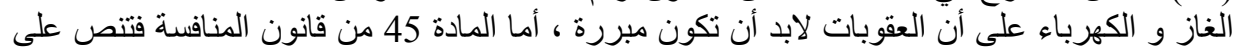

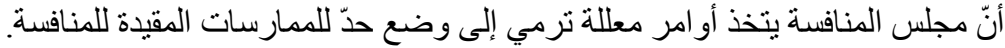

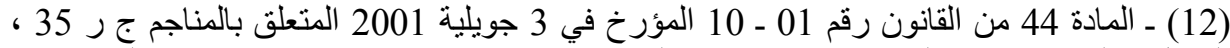
المعدل و المتمم بموجب القانون رقم 14 - 05 المؤرخ في 24 فبر اير 2014 يتضندن قانون المناجم ، ج 
(13) ـ المادة 132 من القانون رقم 02 - 01 المؤرخ في 5 فيفري 2002 المتعلق بالكهرباء

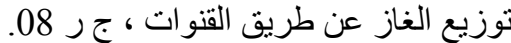

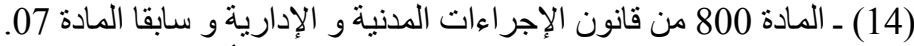

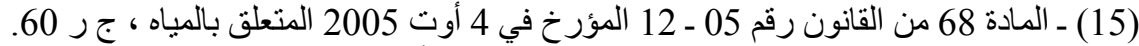
(16) ـ المادة 12 من القانون رقم 05 - 07 المؤرخ في 28 أفريل 2005 المنعلق بالمحروقات ، جر المر

(17) ـ المادة 13 من القانون رقم 2000 - 03 المؤرخ في 5 أوت 2000 المتعلق بالقو اعد العامة للبريد

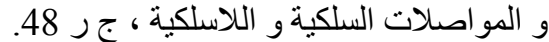

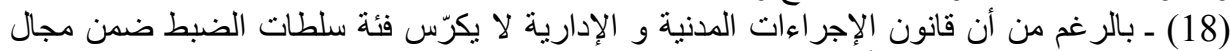

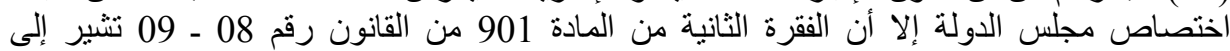

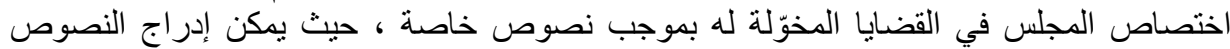
المنشئة لسلطات الضبط في هذا المجال.

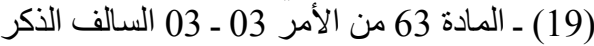
(20) ـ قرار مجلس الدولة المؤرخ في 01 أفريل 2003 ، مجلة مجلس الدولة ، 2005 ، 06 ، ص

(21) - سواء بالنسبة لقرارات اعتماد الوسطاء( المادة 09 من قانون 03 - 04 و بالنسبة لقرارات

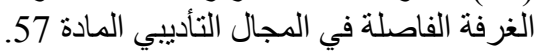

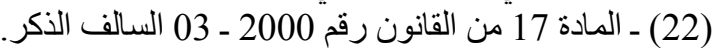
(23) - و هو أجل يمكن أن يقتصر على 8 أبام في حالة اتخاذ ندابير مؤقتة من طرف المجلس للحد من

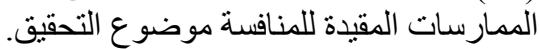

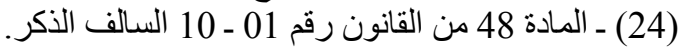

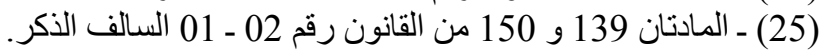

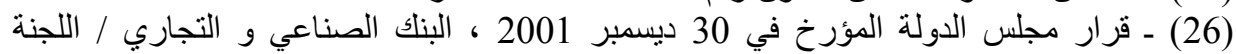

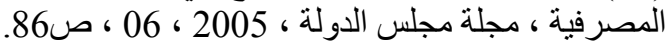
(27) ـ المادة 33 من القانون 03 - 04 السالف الذئ الذكر.

(28) - حيث تتص المادة 152 من الدستور في فقرنها الثالثة على أن المحكمة العليا و مجلس الدولة يضمنان توحيد الاجتهاد القضائي. 